\title{
Thermal Properties of Asphalt Mixtures Modified with Conductive Fillers
}

\author{
Byong Chol Bai, ${ }^{1}$ Dae-Wook Park, ${ }^{2}$ Hai Viet Vo, ${ }^{2}$ Samer Dessouky, ${ }^{3}$ and Ji Sun Im $^{1}$ \\ ${ }^{1}$ Center for C-Industry Incubation, Korea Research Institute of Chemical Technology, 141 Gajeong-ro, Yuseong, \\ Daejeon 305-600, Republic of Korea \\ ${ }^{2}$ Department of Civil Engineering, Kunsan National University, San 68 Miryong-dong, Kunsan, Chollabuk-do 573-701, \\ Republic of Korea \\ ${ }^{3}$ Department of Civil and Environmental Engineering, The University of Texas at San Antonio, One UTSA Circle, \\ San Antonio, TX 78249-0668, USA \\ Correspondence should be addressed to Dae-Wook Park; parkdw@hotmail.com
}

Received 29 December 2014; Revised 6 May 2015; Accepted 24 May 2015

Academic Editor: Xuping Sun

Copyright (C) 2015 Byong Chol Bai et al. This is an open access article distributed under the Creative Commons Attribution License, which permits unrestricted use, distribution, and reproduction in any medium, provided the original work is properly cited.

\begin{abstract}
This paper investigates the thermal properties of asphalt mixtures modified with conductive fillers used for snow melting and solar harvesting pavements. Two different mixing processes were adopted to mold asphalt mixtures, dry-and wet-mixing, and two conductive fillers were used in this study, graphite and carbon black. The thermal conductivity was compared to investigate the effects of asphalt mixture preparing methods, the quantity, and the distribution of conductive filler on thermal properties. The combination of conductive filler with carbon fiber in asphalt mixture was evaluated. Also, rheological properties of modified asphalt binders with conductive fillers were measured using dynamic shear rheometer and bending beam rheometer at gradespecific temperatures. Based on rheological testing, the conductive fillers improve rutting resistance and decrease thermal cracking resistance. Thermal testing indicated that graphite and carbon black improve the thermal properties of asphalt mixes and the combined conductive fillers are more effective than the single filler.
\end{abstract}

\section{Introduction}

Chemical melting agents have been widely used in snowremoving over asphalt pavements in metropolitan areas of South Korea. However, the chemical agents were known to be detrimental to environment $[1,2]$. Silica sand was also used to increase skid resistance of iced surface but with porous asphalt pavements it reduces the drainage capability. Nowadays, thermo- or electrical snow melting asphalt pavements are more appropriate and reasonable to use than conventional chemical snow melting agents, because they are environment friendly, safe, efficient, and sustainable.

Wang et al. [3] conducted experimental study of snow and ice melting process on concrete pavement using geothermal tail water. The physical properties such as density and porosity of snow melting pavement linked with ambient conditions affect melting process. The results showed that tail water temperature of around $40^{\circ} \mathrm{C}$ was enough for melting snow on the pavements. Liu et al. [4] performed a research on electrically conductive porous asphalt concrete by adding conductive filler such as steel fibers and steel wool. The electrical conductivity of porous asphalt concrete was investigated. The results showed that porous asphalt concrete with long steel wool with small diameter had better conductivity than that of short steel fibers with larger diameter. They also found that $10 \%$ of steel wool by volume in asphalt binder is an optimal content to get a maximum conductivity, a good induction heating rate, and an acceptable strength. Vaidya and Allouche [5] developed a conductive geopolymer concrete mixed with carbon fiber for the use in health monitoring applications for infrastructure. The optimum carbon fiber content was determined to get electrical percolation. They suggested that carbon fiber reinforced (CFR) geopolymer cement exhibited better electrical conductivity compared to CFR-ordinary Portland cement. Park et al. [6] investigated the thermal conductivity of asphalt pavement with an addition of graphite 
powder as conductive filler. It was concluded that the time for snow melting process could be shortened by increasing the amount of graphite content; about half amount of the time could be reduced with 20 percent graphite added. Wu et al. [7] have found that the addition of small amounts of expensive fibers to larger amounts of cheaper conductive fillers could be a promotion of economic efficiency. Mixed conductive fillers have remarkable advantages over single powder filler at the same total content with respect to the conductivity. Vo et al. [8] investigated the potential of using graphite as conductive filler for snow melting pavements and recommended 15 percent graphite content, by volume of asphalt binder, in the mixture as a reasonable amount.

In this paper, the thermal conductivity of asphalt mixture modified with conductive filler was investigated based on different graphite and carbon black contents and two mixing processes; dry-mixing and wet-mixing processes. Four graphite and carbon black contents of 5, 10, 15, and 20 percent by volume of asphalt binder were used to produce the asphalt mixture. Control asphalt mixture (without conductive filler) was used to compare the results against the modified asphalt mixture. The thermal conductivity of asphalt mixture was measured for control and mixing processes by surface probe type. Dynamic shear rheometer (DSR) and bending beam rheometer (BBR) tests were used to measure the rheological properties of the modified asphalt binders. The effect of mixed fillers on the thermal properties of asphalt mixtures was investigated with the combination of carbon fiber and graphite to comprehend the appreciable effectiveness over single conductive filler. The distribution of conductive fillers in the mixture was observed by scanning election microscope (SEM) images.

\section{Experimental Method}

This section covers the materials used to produce the modified asphalt mixture followed by the sample preparation and testing method of the study.

2.1. Materials. Asphalt binder, PG 64-22, was used for all mixes in the study. The conductive fillers were graphite (with particle size of $150 \mu \mathrm{m})$ consisting of $98.9 \%$ carbon, $0.2 \%$ ash and $0.03 \%$ iron, and carbon black $(0.042 \mu \mathrm{m})$ with $0.2 \%$ ash. Carbon fiber was a combining conductive filler, fiber diameter of $10 \mu \mathrm{m}$ and average length of $5 \mathrm{~mm}$. Electrical resistivity of carbon fiber, graphite, and carbon black is $10^{-3}$, $10^{-4}$, and $10^{-2} \Omega \mathrm{cm}$, respectively.

Aggregates obtained from local sources were used in the two mixing processes of the modified asphalt mixture. It is the author's belief that local river gravel aggregates will enhance the effect of filler conductivity in the asphalt mixture in higher extent than the high quality of expensive aggregates. The mix design includes an optimum asphalt content of 5.3 percent and aggregate gradation as shown in Table 1.

2.2. Sample Preparation. The asphalt binder, PG 64-22, was mixed with four different conductive filler contents, 5, 10, 15, 20 percent by volume of asphalt binder. Aggregate was
TABLE 1: Aggregate gradation used in this study.

\begin{tabular}{lccccccccc}
\hline Sieve size $(\mathrm{mm})$ & 19 & 13 & 10 & 5 & 2.5 & 0.6 & 0.3 & 0.15 & 0.075 \\
\hline $\begin{array}{l}\text { Percent passing } \\
(\%)\end{array}$ & 100 & 92 & 80 & 51 & 30 & 17 & 11 & 7 & 3 \\
\hline
\end{tabular}

preheated to the mixing temperature of $170^{\circ} \mathrm{C}$. By proceeding the mixing method done by Park and Vo $[6,8]$, there are two ways to add conductive fillers into the mixture and they have certain effects on the conduction of heat in the asphalt mixture. For the wet-mixing process, conductive filler was blended into the asphalt using a high-speed shear mixer and a hot plate. The asphalt was heated in a high performance oven to a temperature of $180^{\circ} \mathrm{C}$. The conductive filler was then added to the asphalt slowly and stirred from 500 to $3500 \mathrm{rpm}$ for 30 minutes until full dissolution is obtained. After mixing, full dispersion was achieved and no phase separation was noticed during the mixing process. The mix of asphalt binder and conductive filler was stored one hour in the oven at the mixing temperature before mixing with the aggregate. For the dry-mixing process, conductive filler was mixed with heated aggregates in the mixer before blending with asphalt. In both mixing processes, the same amount of conductive filler content was subtracted from the filler content (passing sieve size $0.075 \mathrm{~mm}$ ) of the aggregate. The dry-mixing process was applied for mixtures with combined conductive filler of carbon fiber and graphite. Preliminary experiments had found that carbon fiber of more than 2 percent is hard to disperse evenly in the mixture with normal mixing techniques $[5,7]$. Therefore, 0.5 percent carbon fiber was alternately combined with 5, 10 15, and 20 percent graphite and added into the mixture. All asphalt concrete mixtures were prepared in the laboratory using a mechanical, rotational mixer. Compaction following the Superpave volumetric mix design procedures to mold $100 \mathrm{~mm}$ diameter and $64 \mathrm{~mm}$ height specimens was performed. For each conductive filler content, four replicates were molded for the conductivity test.

2.3. Testing. The rheological properties of asphalt binder modified with conductive filler were investigated using DSR and BBR tests. The DSR test is used to characterize the viscoelastic behavior of asphalt binders at high and intermediate service temperatures. The BBR test is used to characterize the behavior of asphalt binders at low temperatures to determine their resistance to thermal cracking. The DSR tests were conducted for unaged and rolling thin film oven (RTFO) aged asphalt binders at $64^{\circ} \mathrm{C}$. The BBR tests were conducted for asphalt binders, after RTFO and pressure aging vessel (PAV), at $-12^{\circ} \mathrm{C}$. The RTFO is used to simulate the aging process of the bitumen from the heating process during construction and laydown operation. Long-term aging was simulated using the RTFO followed by the PAV. The PAV is used to simulate aging conditions of 7-10 years of service [9].

The complex shear modulus, $\left|G^{*}\right|$, and the phase angle, $\delta$, were obtained from the DSR testing. The test was conducted in a stress-controlled mode at a frequency of $10 \mathrm{rad} \mathrm{s}^{-1}$ for three replicate specimens. The rutting parameter, $\left|G^{*}\right| / \sin \delta$, was calculated for the unaged and RTFO aged specimens. 
TABLE 2: Rheological properties of modified asphalt binders.

\begin{tabular}{|c|c|c|c|c|c|}
\hline Filler type & $\begin{array}{c}\text { Conductive filler } \\
\text { content } \\
(\% \text { by vol. })\end{array}$ & $\begin{array}{c}G^{*} / \sin \delta \text { for unaged } \\
\text { binder } \\
(\mathrm{kPa})\end{array}$ & $\begin{array}{c}G^{*} / \sin \delta \text { for RTFO aged } \\
(\mathrm{kPa})\end{array}$ & $\begin{array}{l}\text { Stiffness, } S(t) \\
(\mathrm{MPa})\end{array}$ & $m$-value \\
\hline Control & 0 & 1.8 & 3.5 & 206 & 0.37 \\
\hline \multirow{4}{*}{ Graphite } & 5 & 2.0 & 4.5 & 257 & 0.35 \\
\hline & 10 & 2.2 & 4.5 & 265 & 0.32 \\
\hline & 15 & 2.2 & 4.6 & 297 & 0.30 \\
\hline & 20 & 2.3 & 5.5 & 343 & 0.27 \\
\hline \multirow{4}{*}{ Carbon black } & 5 & 2.2 & 4.7 & 261 & 0.37 \\
\hline & 10 & 2.4 & 4.8 & 275 & 0.34 \\
\hline & 15 & 2.5 & 4.8 & 291 & 0.32 \\
\hline & 20 & 2.5 & 5.4 & 325 & 0.31 \\
\hline
\end{tabular}

The BBR testing was conducted on four replicate beams and the creep bending stiffness, $S(t)$, and $m$-value measurements were recorded. Bulk density of asphalt mixture containing various conductive fillers contents was measured according to KS F2366 [10].

The thermal conductivity test was conducted to investigate heat flow capacity in the modified asphalt mixture which can be effectively used in snow melting and solar energy harvesting pavements based on ASTM D5334-08 [11]. Thermal conductivity of mixtures was measured using a surface probe type of QuickLine-30. The probe applies a dynamic measurement method which reduces the time of thermal conductivity measurements to $10-16$ minutes. A $5 \mathrm{~cm}$ diameter surface probe was used to measure the thermal conductivity of the asphalt mixture specimens. Once the surface probe is in contact with the specimen a constant current was then applied. The thermal conductivity is calculated based on the temperature difference between initial temperature and final temperature after applying heat. The measurement range is 0.3 to $2.0 \mathrm{~W} \mathrm{~m}^{-1} \mathrm{~K}^{-1}$ for thermal conductivity and -10 to $50^{\circ} \mathrm{C}$ for temperature, respectively. The measurement was done with three different positions on sample surface. To ensure a good contact and minimize the measurement error, graphite powders were dispersed evenly to fill the gaps between the probe and specimen surface. The accuracy of thermal conductivity test is 10 percent of reading. The thermal conductivity is calculated as follows:

$$
k=\frac{Q}{4 \pi\left(T_{2}-T_{1}\right)} \ln \left(\frac{t_{2}}{t_{1}}\right),
$$

where $k$ is thermal conductivity $\left(\mathrm{W} \mathrm{m}^{-1} \mathrm{~K}^{-1}\right), Q$ is heater power (W), $T_{1}$ and $T_{2}$ are initial and final measured temperature $(\mathrm{K})$, and $t_{1}$ and $t_{2}$ are initial and final time (sec).

\section{Analysis of Test Results}

This section covers the analysis and discussion of the testing results of rheological properties of modified asphalt binders and thermal conductivity of asphalt mixture modified with conductive filler.
3.1. Rheological Properties. The test results of DSR at $64^{\circ} \mathrm{C}$ are summarized in Table 2. Unaged and RTFO aged modified asphalt binders are presented. Results suggested that all conductive fillers contents have met the specification of rutting parameter, $G^{*} / \sin \delta$, which is a minimum of $1 \mathrm{kPa}$ for unaged and a minimum of $2.2 \mathrm{kPa}$ for the RTFO aged asphalt binder. As graphite or carbon black content increases, the value of $G^{*} / \sin \delta$ is increased. It indicates that asphalt binder becomes stiffer and more resistant to rutting with increased graphite or carbon black content.

The test results of BBR are also summarized in Table 2. The coefficient of variation of the four replicates at each graphite and carbon black content was less than 10\%. For asphalt binder to be flexible with high resistance to low temperature cracking, a maximum creep stiffness of $300 \mathrm{MPa}$ and a minimum $m$-value of 0.3 are specified. Results suggested that as conductive filler content increases, $S(t)$ is increased and $m$-value is decreased. It indicates that asphalt binder becomes brittle and less resistant to low temperature cracking with increased graphite or carbon black content. It is remarked that graphite content of more than $15 \%$ and carbon black content of generally more than $20 \%$ will have less resistance to thermal cracking as indicated by the outof-range specifications. There was no significant difference between the effect of graphite and carbon black on rheological properties of asphalt binder.

3.2. Thermal Conductivity. The average thermal conductivity measurements for control, dry- and wet-mixing asphalt mixture modified with conductive filler, are shown in Figure 1. The results showed that thermal conductivity is increased as the graphite or carbon black content increases. In general, the wet process also showed a slightly increased thermal conductivity compared to the dry process due to the well distribution of conductive filler particles within the asphalt mixtures. In the case of the wet process, even and uniform filler distribution is more pronounced compared to the dry process; however, the increase is generally insignificant and there is a requirement of specific mixer for premixing conductive filler and asphalt. Besides, graphite is apparently dominant in the improvement of thermal conductivity as 
TABLE 3: Summarizing thermal properties of asphalt mixture modified with conductive filler (wet mix).

\begin{tabular}{|c|c|c|c|c|c|}
\hline Filler type & $\begin{array}{c}\text { Conductive filler } \\
\text { content } \\
(\% \text { by vol. })\end{array}$ & $\begin{array}{l}\text { Bulk density } \\
\quad\left(\mathrm{kg} \mathrm{m}^{-3}\right)\end{array}$ & $\begin{array}{c}\text { Thermal conductivity, } \\
\qquad k\left(\mathrm{~W} \mathrm{~m}^{-1} \mathrm{~K}^{-1}\right)\end{array}$ & $\begin{array}{l}\text { Specific heat, } C \\
\quad\left(\mathrm{~J} \mathrm{~kg}^{-1} \mathrm{~K}^{-1}\right)\end{array}$ & $\begin{array}{l}\text { Thermal diffusivity } \\
\qquad\left(\mathrm{mm}^{2} \mathrm{~s}^{-1}\right)\end{array}$ \\
\hline Control & 0 & 2282 & 1.866 & 959 & 0.853 \\
\hline \multirow{4}{*}{ Graphite } & 5 & 2288 & 1.979 & 935 & 0.925 \\
\hline & 10 & 2285 & 1.983 & 906 & 0.958 \\
\hline & 15 & 2281 & 2.030 & 886 & 1.004 \\
\hline & 20 & 2274 & 2.089 & 864 & 1.063 \\
\hline \multirow{4}{*}{ Carbon black } & 5 & 2321 & 1.911 & 944 & 0.872 \\
\hline & 10 & 2314 & 1.916 & 932 & 0.888 \\
\hline & 15 & 2298 & 1.953 & 922 & 0.922 \\
\hline & 20 & 2276 & 1.962 & 920 & 0.937 \\
\hline \multirow{5}{*}{ Carbon fiber + graphite } & $0.5+0$ & 2304 & 1.930 & 909 & 0.922 \\
\hline & $0.5+5$ & 2328 & 2.025 & 867 & 1.003 \\
\hline & $0.5+10$ & 2338 & 2.115 & 816 & 1.109 \\
\hline & $0.5+15$ & 2319 & 2.158 & 814 & 1.143 \\
\hline & $0.5+20$ & 2316 & 2.177 & 810 & 1.160 \\
\hline
\end{tabular}

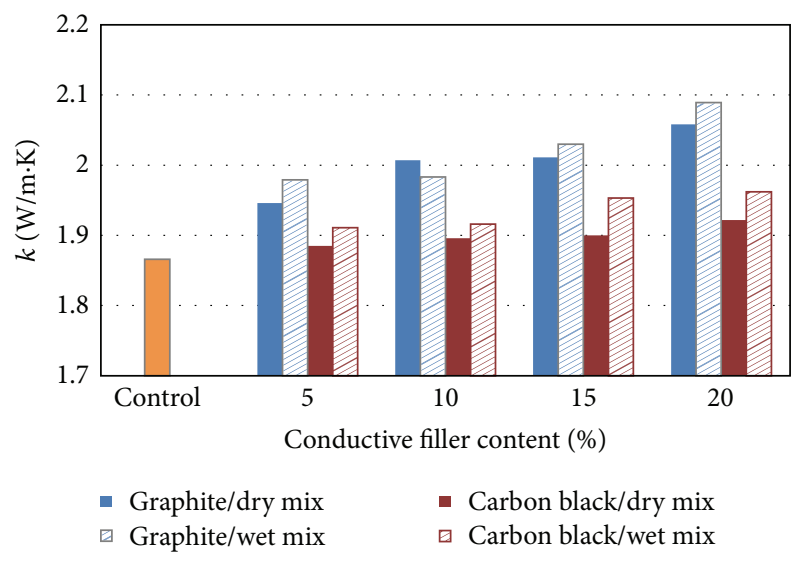

Figure 1: Thermal conductivity measurements of asphalt mixture modified with conductive filler.

compared to carbon black. As seen in Figure 2, clusters of small carbon black particles are discrete while graphite particles are widespread in a larger scale. Accordingly, graphite was selected to supplement with carbon fiber as combined conductive filler using dry process.

Asphalt concrete containing single carbon fiber of $0.5 \%$ shows the increase in thermal conductivity compared to control specimen as shown in Figure 3. Carbon fiber plays a long range conduction role in asphalt mixture (see Figure 4(a)). Furthermore, thermal conductivity strongly increases as combining $0.5 \%$ carbon fiber with $5 \%, 10 \%$, and $15 \%$ graphite; however, with $20 \%$ graphite combined, the increase is no longer significant. A high level of conductive fillers could have affected the mechanical properties of asphalt concrete and increased air voids content. Due to a linking effect (see Figure 4(b)), which is defined as the fact that fibers may link several isolated conductive areas and bypass the obstacles in conductive network created by some aggregates, carbon fiber may connect conductive areas or chains together and form conductive paths. Therefore, the combined conductive filler with carbon fiber, at a reasonable amount, shows an advance and efficiency in improving thermal conductivity of modified asphalt concrete as compared to a significant amount of single conductive filler.

The thermal diffusivity, $\alpha\left(\mathrm{mm}^{2} \mathrm{~s}^{-1}\right)$, is given by the following relationship:

$$
\alpha=\frac{k}{\rho C},
$$

where $k=$ thermal conductivity $\left(\mathrm{W} \mathrm{m}^{-1} \mathrm{~K}^{-1}\right) ; \rho=$ density $\left(\mathrm{kg} \mathrm{m}^{-3}\right)$; and $C=$ specific heat $\left(\mathrm{J} \mathrm{kg}^{-1} \mathrm{~K}^{-1}\right)$. The thermal properties of modified asphalt mixtures are summarized in Table 3. The bulk density of modified asphalt mixture decreases as the conductive filler increases due to replacing the mineral filler content of the aggregate. The specific heat is lower at a higher conductive filler content. The thermal diffusivity slightly increases with an increase in conductive filler content.

\section{Conclusions}

In this paper, the effect of various and combined conductive fillers, graphite, carbon black, and carbon fiber used for improving thermal conductivity of snow melting pavement, was investigated. Two different mixing processes, dry and wet processes, were used to mold asphalt mixes.

The rheological properties of modified asphalt binders indicated that graphite and carbon black increase rutting parameter, $G^{*} / \sin \delta$, at high temperature but reduce resistance to low temperature cracking. Therefore, graphite and carbon black have a potential to increase rutting resistance but decrease thermal cracking resistance. The wet-mixing 


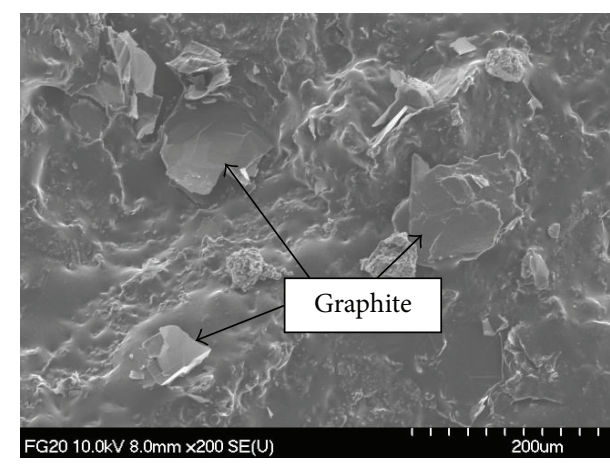

(a)

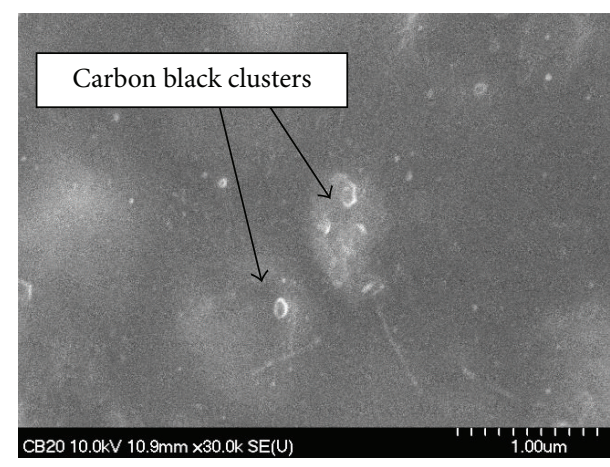

(b)

FIGURE 2: SEM images of (a) graphite and (b) carbon black in the mixture.

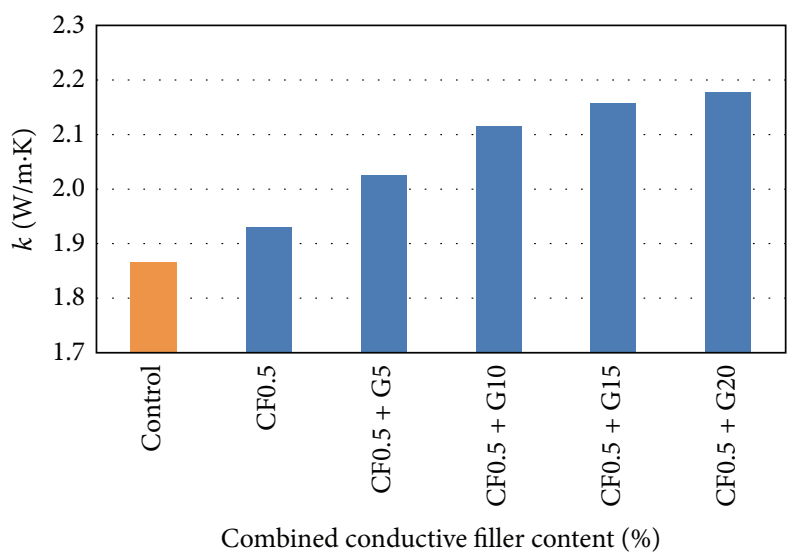

FIgURE 3: Thermal conductivity measurements of asphalt mixtures modified with combined conductive filler (CF: carbon fiber, G: graphite).

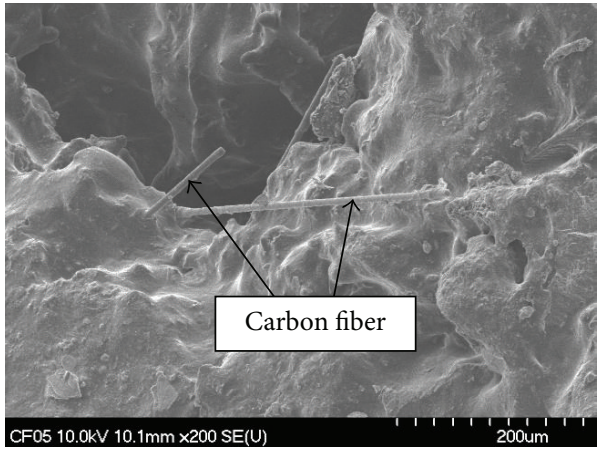

(a)

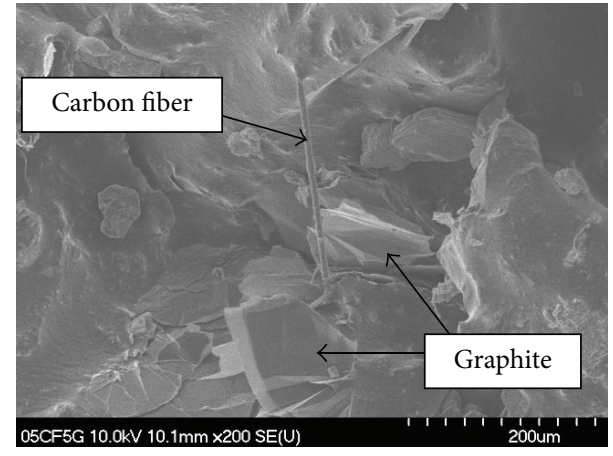

(b)

FIGURE 4: SEM images of (a) carbon fiber and (b) carbon fiber with graphite in the mixture.

process provides a better distribution of conductive filler in asphalt mixtures; however, the dry process can be performed more simply.

The thermal testing results suggested that both graphite and carbon black improve thermal properties of asphalt mixes; but graphite is significantly more effective. The combination of conductive filler with a certain amount of carbon fiber brings significant effects and advantages over single conductive filler. The authors propose conducting further laboratory testing procedures with various aggregate and binder types and microstructure analysis to have a comprehensive performance evaluation of asphalt mixture modified with conductive filler.

\section{Conflict of Interests}

The authors declare that there is no conflict of interests regarding the publication of this paper. 


\section{Acknowledgment}

This research was supported by Basic Science Research Program through the National Research Foundation of Korea (NRF) funded by the Ministry of Education (no. 2014R1A1A4A01004293).

\section{References}

[1] J. B. Edwards, "Weather-related road accidents in England and Wales: a spatial analysis," Journal of Transport Geography, vol. 4, no. 3, pp. 201-212, 1996.

[2] F. Hutchison, "Environmental pollution from highway deicing on highways," Journal of Soil and Water Conservation, vol. 25, no. 4, pp. 144-146, 1970.

[3] H. Wang, J. Zhao, and Z. Chen, "Experimental investigation of ice and snow melting process on pavement utilizing geothermal tail water," Energy Conversion and Management, vol. 49, no. 6, pp. 1538-1546, 2008.

[4] Q. Liu, E. Schlangen, Á. García, and M. van de Ven, "Induction heating of electrically conductive porous asphalt concrete," Construction and Building Materials, vol. 24, no. 7, pp. 1207-1213, 2010.

[5] S. Vaidya and E. N. Allouche, "Experimental evaluation of electrical conductivity of carbon fiber reinforced fly-ash based geopolymer," Smart Structures and Systems, vol. 7, no. 1, pp. 2740, 2011.

[6] D. W. Park, S. Dessouky, and S. D. Hwang, “Thermo-physical properties of graphite-modified asphalt mixture and numerical analyses for snow melting pavement," in Sustainability, EcoEfficiency, and Conservation in Transportation Infrastructure Asset Management, pp. 87-94, CRC Press, Pisa, Italy, 2014.

[7] S. Wu, L. Mo, Z. Shui, and Z. Chen, "Investigation of the conductivity of asphalt concrete containing conductive fillers," Carbon, vol. 43, no. 7, pp. 1358-1363, 2005.

[8] H. V. Vo, D. Park, and S. Dessouky, "Simulation of snow melting pavement performance using measured thermal properties of graphite-modified asphalt mixture," Road Materials and Pavement Design, 2015.

[9] F. L. Roberts, P. S. Kandhal, E. R. Brown, D. Y. Lee, and T. W. Kennedy, Hot Mix Asphalt Materials, Mixture Design, and Construction, National Asphalt Pavement Association Education Foundation, Lanham, Md, USA, 1996.

[10] Korea Standard (KS), "Standard test method for specific bulk gravity of compacted asphalt mixtures," KS F2353, Korea Standard Information Center, 2010.

[11] ASTM International, "Standard test method for determination of thermal conductivity of soil and soft rock by thermal needle probe procedure," ASTM D5334-08, ASTM International, West Conshohocken, Pa, USA, 2008. 

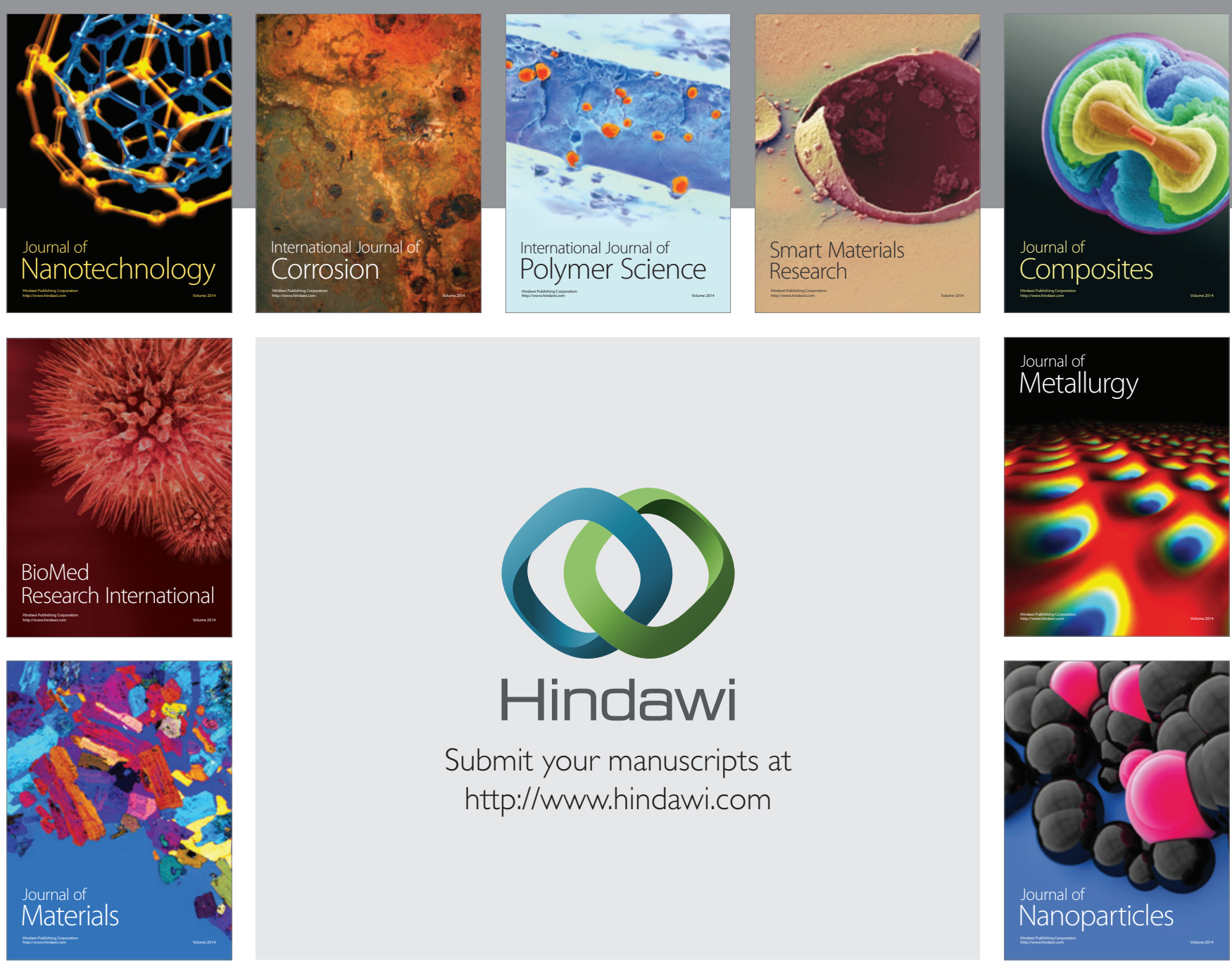

Submit your manuscripts at http://www.hindawi.com
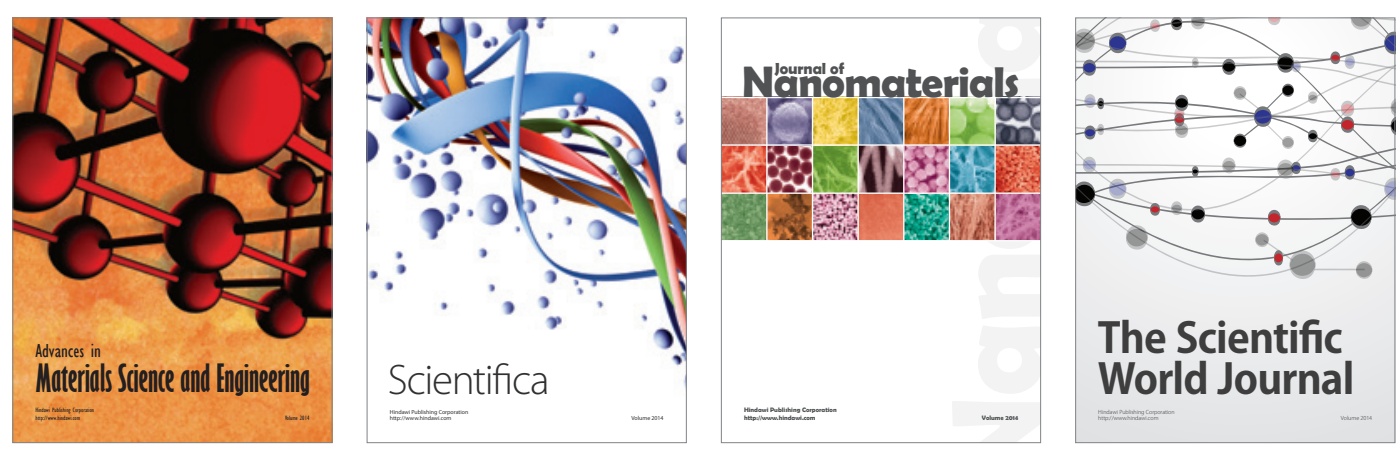

\section{The Scientific World Journal}
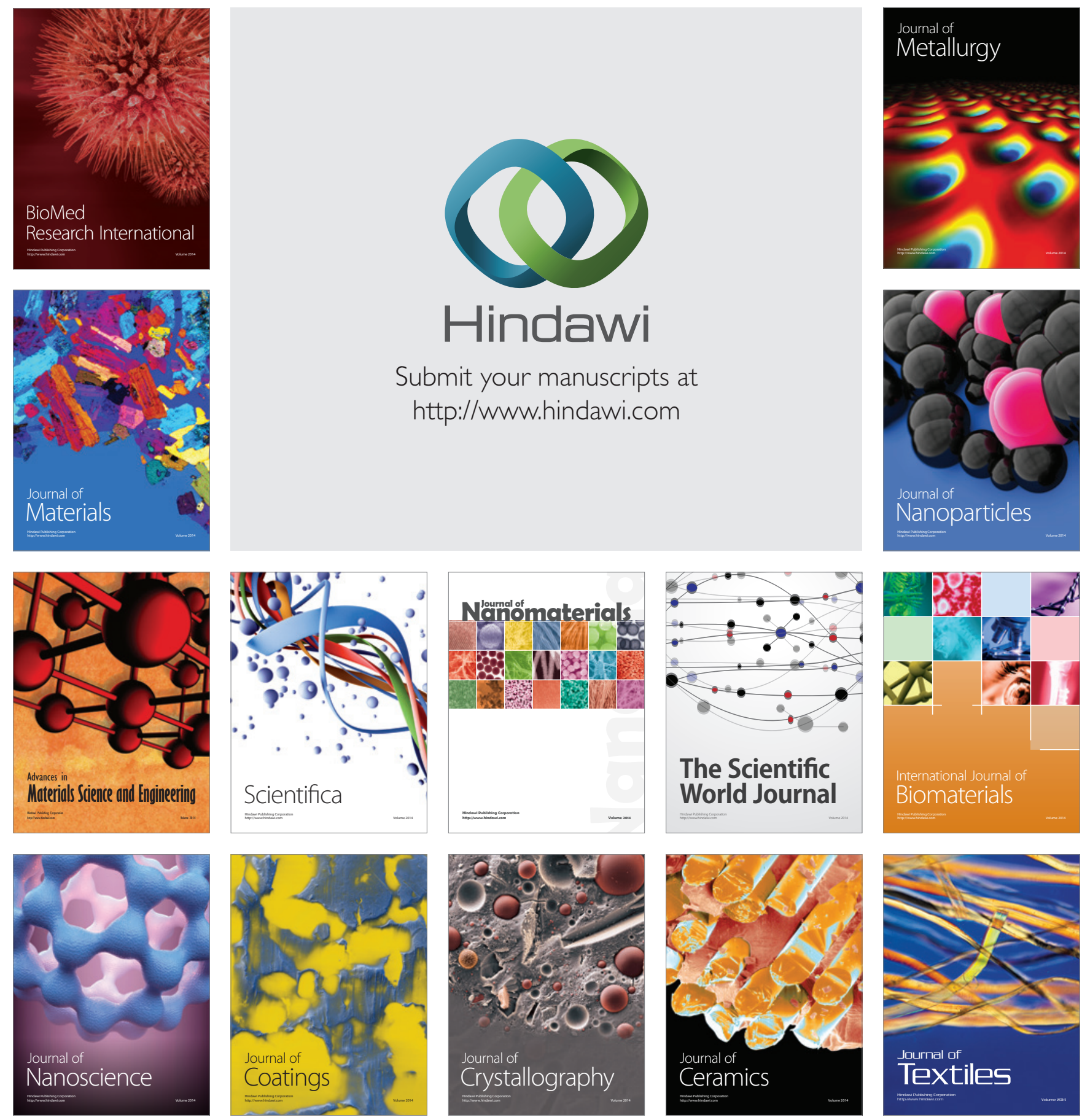